\title{
Status, Causes and Countermeasures of Team Stability of the Technology Workers in State-owned Enterprise Research
}

\author{
Li Daoyi \\ School of Management \\ Wuhan University of Technology \\ Wuhan China \\ e-mail: 358040251@qq.com
}

\author{
Cheng Yanxia \\ School of Management \\ Wuhan University of Technology \\ Wuhan China \\ e-mail: chengyanxia221@126.com
}

\begin{abstract}
Based on the CAST " science and technology workers of state-owned enterprises survey" project, we analyzed the current situation of stability of state-owned enterprises scientists team and found tremendous pressure, lack of state-owned cultural identity, professional development of space constraints, salary and contribution mismatches academic status and power mismatches lead to the lack of stability of he technology workers in state-owned enterprise. On this basis, the paper proposes several recommendations for state-owned enterprise to strengthen the stability of the of scientists team.
\end{abstract}

Keywords- science and technology workers; team stability; state-owned enterprise; industrial chain ; technological innovative

\section{INTRODUCTION}

With the rapid development of modern science and technology, social and economic development have become increasingly demanding for science and technology. State-owned enterprises as the mainstay of the national economy, is particularly urgent for knowledge, talent, technology, demand. Human resources with knowledge and high-tech is not only a key factor for the growth of state-owned enterprises, but also the soul and backbone of its survival and development. Team stability of scientific and technical personnel plays an important role for the sustained and stable development of the organization. Once the sudden loss of personnel, it is easy to make enterprises face significant challenges, the team stability of scientific and technological workers has a significant impact on the development of the state-owned enterprises and the profit growth.. Therefore, In view of the situation of state-owned enterprise of science and technology workers team stability, analyzing the causes of the lack of stability and put forward relevant countermeasures, have a certain role in promoting the development of state-owned enterprises.

Based on the CAST " science and technology workers of state-owned enterprises survey" project, take the old, middle and green team members of the research team in the state-owned enterprises as the object of investigation, we conducted a survey and interview questionnaire on internal transfer willingness and job hopping related to the stability of the team stability. Survey have been implemented from January 2011 to November 2012, covering 19 provinces and 4 municipalities. The research object is the scientific and technical workers of the state- owned enterprises, involving state-owned enterprise technical development personnel. The survey uses scientific and reasonable method to extract the sample, and the survey is strict following the principle of social investigation, ensure the scientific, objectivity and accuracy. A total of 8200 questionnaires were distributed, 7425 valid questionnaires were recovered, the recovery rate was $90.5 \%$.

\section{DEFINITION OF SCIENTIFIC AND TECHNICAL WORKERS OF STATE-OWNED ENTERPRISES}

Scientific and technical workers is a concept often used by the government and the scientific community, refers to the scientific and technical personnel, and the definition of whom so far has not been strictly defined. Wenyan (2003) defined science and technology worker: people in the field of natural science and mastering relevant professional knowledge, engaged in scientific and technological research, dissemination, promotion and application, and specialized technical management. Since then, some researchers have made a further discussion on the definition and connotation of the scientific and technical workers, although it did not give a clear definition, but proposed the scientific and technological workers as a professional group to look at, and pointed out that the scientific and technological workers are the in modern society, with the corresponding scientific and technological work as a career, actually engaged in scientific and technical knowledge to produce a systematic, development, dissemination and application of personnel activities.

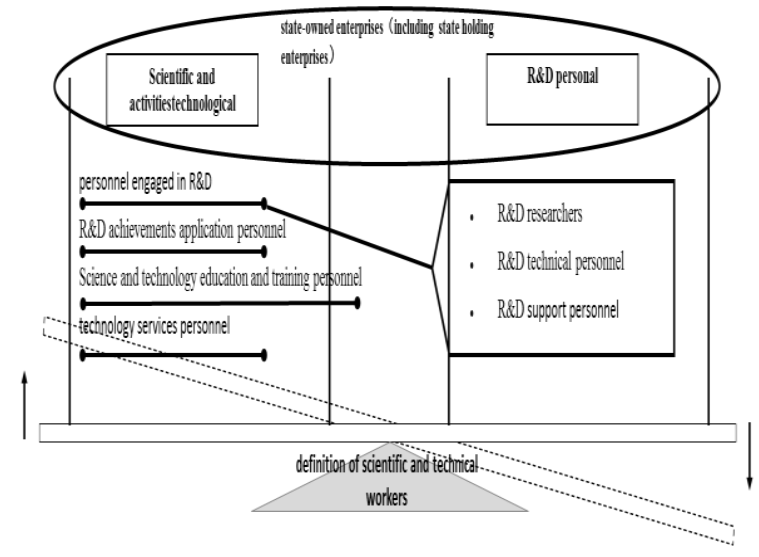

Figure 1.definition of scientific technical workers of state-owned enterprises 
Scientific and technical workers have become very important in modern society, and play an important role. This professional group takes the modern science and technology work as its own responsibility, is engaged in the research, the development, the application, the dissemination, the maintenance and the management and so on, obtains the science and Technology Fund and the reasonable reward.

As a unique concept of our country, the scientific and technological workers are widely used in the central file after the founding of new China. The definition of the concept of scientific and technological workers has some common characteristics, and there are some differences. Science and technology workers are engaged in science and technology vocational practical on-the-job personnel quantity, including technical personnel and R \& D staff; human resources in science and technology in addition to actually engaged in scientific and technological activities of personnel, including personnel engaged in scientific and technological activities of potential. Related to the concept of integrated science and technology human resource, science and technology activities, scientists and engineers, $\mathrm{R} \& \mathrm{D}$ personnel and technology workers, scientific and technical workers of state-owned enterprises is defined theoretically as in state-owned enterprises and state holding enterprises (hereinafter referred to as state-owned enterprises), personnel engaged in $R \& D$, including $R \& D$ researchers, $R \& D$ technical personnel, $R \& D$ support personnel; R\&D achievements application personnel; technology services personnel.

\section{THE BASIC SITUATION OF WORKERS IN STATE-} OWNED ENTERPRISE TECHNOLOGY TEAM AND THE MAIN REASON FOR THE STABILITY ANALYSIS

\section{A. The basic situation of workers in state-owned enterprise technology team stability}

1) Youth team members lack of focusing on stateowned enterprises, the flow rate is higher turnover

The relative stability of the research team (team member turnover rate at $5 \%$ or less) is an important safeguard for enterprises to achieve sustainable innovation capability. If the team members, especially a large number of reserve forces lost, not only led to increased corporate personnel replacement, damage cohesion, but also weaken the strength of corporate research, bringing the loss of intangible assets, technology, human resources, and ultimately lead to corporate sustainability potential innovation capacity deficiencies. In the survey, "If giving you an opportunity for career choice, what you want to enter the nature of the work unit," young people (30 years and under) sample group, $21.0 \%$ chose the government, 10.4 percent chose the research institutes, $10.0 \%$ chose private enterprises, 15.6 percent chose foreign, only $42.8 \%$ young scientists selected state-owned enterprises. The results showed that young scientists to state-owned cultural identity is not high, state-owned enterprises "episode" is more loss, poor focus to state-owned enterprises. In the survey, "research team member quit ratio" is often or occasionally quit the idea of young scientists accounted for $79.8 \%$, the flow churn middle-aged technology backbone and is much higher than the technical experts.

\begin{tabular}{llllll}
\multicolumn{7}{c}{ TABLE I. Ideal work type of different age } \\
\hline Age & $\begin{array}{l}\text { Government } \\
\text { departments }\end{array}$ & $\begin{array}{l}\text { Research } \\
\text { institutes }\end{array}$ & $\begin{array}{l}\text { State-owned } \\
\text { enterprises }\end{array}$ & $\begin{array}{l}\text { Private } \\
\text { Enterprise }\end{array}$ & $\begin{array}{l}\text { Foreign } \\
\text { companies }\end{array}$ \\
\hline$<30$ & 21.0 & 10.4 & 42.8 & 10.0 & 15.6 \\
$\geq 30$ & 27.2 & 13.5 & 36.2 & 7.4 & 15.7 \\
\hline
\end{tabular}

2) the flow of the middle-aged backbone of the team "to point" obviously

In the investigation "whether you had the idea of job hopping " , 78.4\% of the middle aged sample(30-50 years old) choose never, higher than the stability of junior team members. When the idea of a job hopping has shown up, the backbone of the middle-aged team rarely take the initiative to seek Recruitment Information , 19.1\% of them will work through the former partner or friend referral jumped to the new company , $14.0 \%$ of them through the headhunter , $36.7 \%$ of them is by "poaching" of other company. The characteristics of the loss flow of the middle-aged team members are very different from that of the young, relative to the young members initiatively to find a job hopping, middle aged members are more likely forced to do that. Once that appears to loss the backbone members , "butterfly effect" will prompt more backbone members have the consciousness of movement, then affect the overall stability and cohesion of scientific research team .

\begin{tabular}{|c|c|c|c|c|c|c|}
\hline Age & $\begin{array}{l}\text { Active } \\
\text { quit }\end{array}$ & $\begin{array}{l}\text { By } \\
\text { poaching }\end{array}$ & $\begin{array}{l}\text { Work with } \\
\text { former } \\
\text { partners }\end{array}$ & $\begin{array}{l}\text { Headh } \\
\text { unter } \\
\text { Comp } \\
\text { any }\end{array}$ & Total & \\
\hline & & & & & Total & $\begin{array}{l}\text { Sample } \\
\text { size }\end{array}$ \\
\hline$<30$ & 42.0 & 29.6 & 16.4 & 12.0 & 100 & 990 \\
\hline $31-40$ & 34.7 & 30.7 & 16.4 & 18.2 & 100 & 1180 \\
\hline $41-50$ & 25.8 & 42.7 & 21.7 & 9.8 & 100 & 640 \\
\hline $51-60$ & 23.6 & 51.2 & 11.0 & 14.2 & 100 & 127 \\
\hline$\geq 60$ & 33.3 & 60.0 & 6.7 & 0.0 & 100 & 15 \\
\hline
\end{tabular}

Research shows that, $37.5 \%$ of the senior engineers at the age of over 50 wishes to have Internal transfer, as many as $56.3 \%$ of the team's technical experts tend to turn to management positions , "official career" has become more and more popular. According to the survey, most of the

state-owned enterprise management personnel are senior technical personnel in the past. In the research and development team , 30\% of the technical experts are assigned to management positions and are busy with managed affairs ,can't devoted themselves into first line

research which leading to the lack of the top talent of research and development team and restriction of team backbone and reserve forces' growth .

Reasons for the low stability of science and technology workers team in the state-owned enterprises

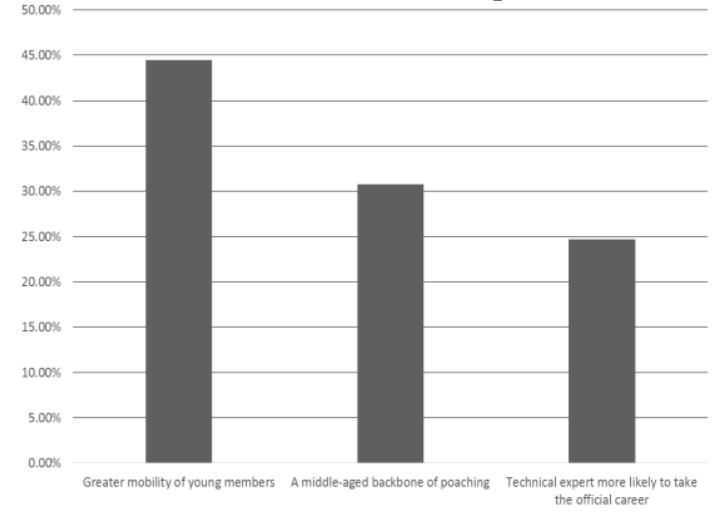


4) Enormous pressure of working life and low cultural identity of state-owned enterprises

In the investigation of work pressure, the respondents feel more sensitive on tasks, work intensity, work difficulty, job responsibility and competitive pressure ; update culture knowledge and improve business ability is particularly prominent in the invisible pressure of higher education level group. In addition, young members of the state-owned enterprise are lack of culture identity . In state owned enterprise culture, "Humanistic care" and "enterprise cohesion" can be guidance and traction to Middle-aged scientists and helps to cooperate with individual and collective goals. But the youth members only consider personal interests gain and loss, the future of personal development and space and difficult to agree with the corporate culture of state-owned enterprises.

5) Personal career development space is restricted and compensation and contribution does not match

By the in-depth interviews with the backbone of scientific research, we learned that the present common problem is the backbone member's career development space is limited and the promotion channel is restricted. Only a few backbone members can become Enterprise scientific research manager. Most scientific research backbone in 40 basically can be rated as senior engineer. After the senior engineer, Whether title promotion space or position promotion space is very small . Middle-aged scientific research backbone need a longer time of precipitation to become a leader. In addition, remuneration and contribution of scientific research backbone members does not match .

6) Academic status and power is not equal

For technical experts, they have reach the peak of the academic, but according to the survey, this kind of person is more need to have some voice and power. Therefore, in the research team, it's common that technical experts become officer. The main reason is scientific research activities need external resources to support . Administrative position is conductive to allocate resources so that sustainability of research could be better served . Secondly, although the academic has been recognized, to most of the state-owned enterprises administrative power is greater than the academic power .So that official career is the only way to be satisfactory to both sides and achieve the peak of career. Additionally, at the same position level ,administrative department gets more benefits , more power, less stress, higher the degree of respect technical department .

\section{RELEVANT COUNTERMEASURES AND SUGGESTIONS}

\section{A. constructing a unified national talent supply and demand information platform}

First, companies need to improve the overall talent evaluation system elements that constituted of the character, performance, knowledge and ability, implement target management on the contribution of innovative science and technology talents, further overcome heavy qualifications, talent evaluation in the light of the tendency capacity performance.Conmpanies should also adhere to identifying talent, discovering talent, nurturing talent in fair competition and provide more opportunities for talents, especially young innovative scientific research talents.
Second, companies should deepen the reform of the distribution system and establish the mechanism of contribution in return and giving the necessary allowance for the creative work that makes the team members work coincides with the resultant remuneration. In addition, companies must provide support for technical experts to carry out innovation activities and tilt towards equipment configuration, funding and personnel to enable them to give full play to strengths and talents. Once again, companies must work earnestly for the lifelong education of researchers and strengthen political and ideological education and professional ethics education for the researchers, support and encourage high-level scientific and technological personnel to participate in international academic exchanges, various forms of academic conferences and other educational activities, so that the knowledge of innovative science and technology talents could get the full update and the achievements continues.

\section{B. Improving the industrial chain and industrial support, creating industrial clusters, promoting the industrial development to gather talents}

On the basis of the existing industrial policy, the government should make more positive industrial policies, attract and serve the state-owned large and medium-sized enterprises as the breakthrough point, make the service enterprises localization through the policy guidance, focus on supporting the large and medium-sized state-owned enterprises, and give priority to do service work. One is the construction of scientific and technological talent apartment or through cooperation with the real estate business, apply mission rent or group buy to gather talents. In addition, on the industrial park construction, almost all of the parks are in the focus of corporate office space, science and technology workers living environment requests sufficient resources.

The second is based on the government to establish a chain or cluster of basic research and development platform, effective integration of the same or similar industry technology resources by opening equipment and research base, the sharing of scientific data and scientific literature by providing expertise, technical incubators and other services, to avoid compartmentalization of interindustry type, segmentation model of development, strengthen exchange mechanisms associated with laterally between enterprises. Companies should also energize the development of enterprises, reduce costs and enhance the attractiveness of science and technology workers to realize talent aggregation by industrial development.

\section{Strengthening scientific and technological innovative market-oriented operation mechanism}

In order to encourage enterprises 'scientific research and technology development to adapt to changing market, researches needs to commercialized and marketed (transformation rate, the transformation rate). In the choice of scientific research and technology development projects, companies must find the right market entry point to enhance their competitiveness and market share. You can also share part of the risk, to encourage banks to the founder of the new technology business loans, preferential interest rates, investment subsidies and direct funding given to the founder of the development of new 
technologies and other measures to promote scientific research into business. In order to break the monopoly and optimize competition market structure, through technical assistance to help improve the general technological absorptive capacity. Meanwhile, the government should liberalize market access to create dynamic market environment and financing environment, boldly explore and pilot knowledge capital mechanism specific ways, including technological innovations involved in distribution, technical price of shares, scientific and technical personnel holding management, technology development achievements reward.

\section{Establishing state-owned enterprises in favor of original and innovative team culture}

The core of technology innovation is the "man." Science and technology funds expenditure account design should reflect the principle of respecting knowledge and respecting talents, and fully mobilize the creativity and enthusiasm of scientific research personnel. "peopleoriented" man The agreement ideas should be put throughout the whole process of scientific research, from the reform of personnel system and distribution system, It's helpful to establish viable talent incentive mechanism, to create good working conditions for researchers, to improve their income level and tilt towards scientific and technical personnel and key positions. The government should establish a culture environment conducive to the original innovation, foster innovation, bold exploration, pursuit of truth, tolerance of failure, encourage competition, respect for cooperation, love science, light the fame and wealth of good cultural fashion; to establish the integrity of scientific research personnel, the establishment of academic misconduct, increase the punishment of academic misconduct, from the system to cure academic corruption.

\section{REFERENCES}

[1] Borman, W.C., Hanson,M.A, Motowidlo, S.J., Drasgo, F.\&Foster, L.(1998). Computerized adaptive rating scales that measure citizenship performance. Paper Presented at the Thirteenth Annual Conference of the Society for Industrial and organizational Psychology, April,1998, Dallas, TX.

[2] Liang, Kaiguang, Davis, Donald D. Chen, Chao C. \& Xie Jialin(1999) Organizational justice in the grobal context, International Management Division, Academy of Management Chicago1999 Submission.

[3] Podsakoff, P. M. \& Mackenzie, S. B.(1997). Impact of organizational citizenship behavior on Organizational performance: A revie and suggestions for future research. Human Performance 10(2).

[4] Oliver Hart and John Moore, Foundation in complete contracts[R]. The Review of Economic Studies, Special Issue: Co Tracts, 2009,(66).

[5] Alan V.S. Douglas Capital structure and the control of managerial incentives[J]. Journal of Corporate Finance, 2005, (8).

[6] Halbesleben, J. R. B., Neveu, J., Paustian-Underdahl, S. C., \& Westman, M. Getting to the "COR": Understanding the role of resources in conservation of resources theory. Journal of Management, 2014, 40, 1334-1364.

[7] Laffont,Jean-Jacques and David Marti mort. The theory of incentives[J]: The Principal-Agent Model. 2007,(10).

[8] Marx.L.and F.Squintani. Individual accountability in teams[A]. Duke University, Working paper, 2009.

[9] Donald Lien. International accreditation and brain drain's simple model. Economics of Education Review, Volume 25, Issue 3, June 2007.

[10] Michel, J. S., Kotrba, L. M., Mitchelson, J. K., Clark, M. A. and Baltes, B. B., Antecedents of work-family conflict: A metaanalytic review. J. Organiz. Behav.,2011,32: 689-725. doi: 10.1002/job.695

[11] Thatcher J B, Stepina L P, Boyle R J. Turnover of information technology workers: Examining empirically the influence of attitudes, job characteristics, and external markets[J]. Journal of Management Information Systems, 2002, 19(3): 231-261.

[12] Siemsen, E., Roth, A., \& Oliveira, P. Common method bias in regression models with linear, quadratic, and interaction effects. Organizational Research Methods, 2010,13, 456-476

[13] Lim, Sook. "Job satisfaction of information technology workers in academic libraries." Library \& Information Science Research 30.2 (2008): 115-121. 